Revue des patrimoines

Le patrimoine scientifique

\title{
Une statuette des environs de 1400 à l'Hôpital général de Dijon
}

\section{Elisabeth Réveillon}

\section{(2) OpenEdition}

Journals

Édition électronique

URL : http://journals.openedition.org/insitu/4512

DOI : 10.4000/insitu.4512

ISSN : 1630-7305

Éditeur

Ministère de la culture

Référence électronique

Elisabeth Réveillon, «Une statuette des environs de 1400 à l'Hôpital général de Dijon », In Situ [En ligne], 10 | 2009, mis en ligne le 19 mai 2009, consulté le 03 mai 2019. URL : http:// journals.openedition.org/insitu/4512 ; DOI : 10.4000/insitu.4512

Ce document a été généré automatiquement le 3 mai 2019.

\section{(c) $($ i) $(9)$}

In Situ Revues des patrimoines est mis à disposition selon les termes de la licence Creative Commons Attribution - Pas d'Utilisation Commerciale - Pas de Modification 4.0 International. 


\title{
Une statuette des environs de 1400 à l'Hôpital général de Dijon
}

\author{
Elisabeth Réveillon
}

Desservie par une dorure à la poudre peu engageante, une réfection sans finesse de la polychromie du visage et un épais repeint de la chevelure, cette statuette en bois doré ${ }^{1}$ a $\mathrm{pu}$ passer inaperçue au milieu du nombre imposant d'objets mobiliers anciens appartenant à l'Hôpital général de Dijon². À y regarder de plus près, et en faisant abstraction du socle mouluré à faces incurvées rapporté, elle se révèle être l'une des œuvres les plus rares conservées dans cet établissement (fig. $\mathbf{n}^{\circ} \mathbf{1}$ ). 
Figure 1

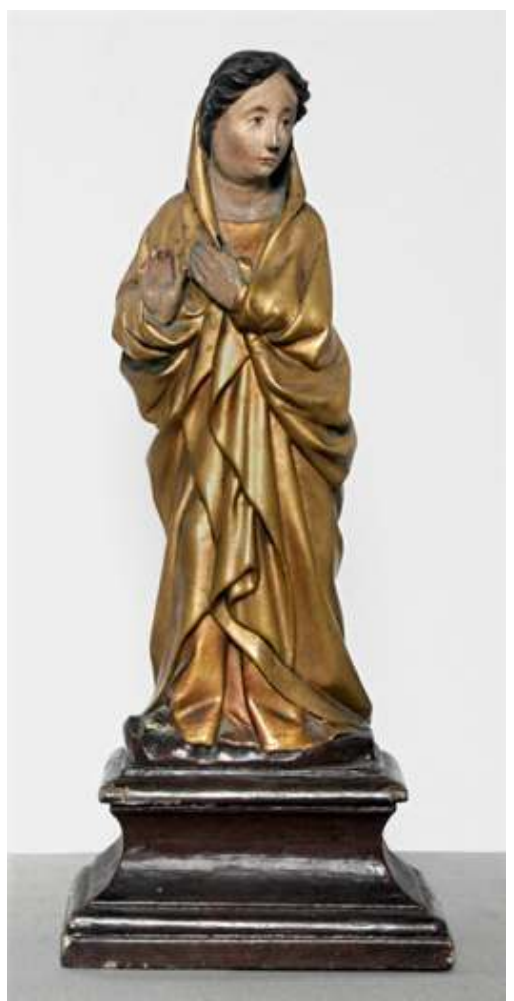

Vierge de l'Annonciation, statuette conservée à l'Hôpital Général de Dijon (Côte-d'Or), vue de face. Jean-Pierre Ramot, 2005

(c) Inventaire général, ADAGP.

2 L'identité du personnage se laisse aisément deviner, bien que la seconde figure du groupe ait disparu : le geste de la Vierge levant la main droite en signe d'accueil du message de l'ange Gabriel est traditionnel dans la représentation médiévale de la scène de l'Annonciation. La main gauche retient près de l'épaule le bord du manteau, dans un mouvement dissymétrique moins courant que l'attitude des deux mains levées ou des bras croisés sur la poitrine. Comme l'indique le visage tourné vers la gauche, l'ange disparu devait être placé à la droite du spectateur, disposition plutôt rare dans l'iconographie de l'Annonciation. La taille réduite de la sculpture désigne de toute évidence une œuvre destinée à la dévotion privée, et le traitement sommaire du revers, une statuette d'applique.

3 Le mouvement de torsion de la silhouette, dont la ligne sinueuse est particulièrement sensible au revers (fig. $\mathbf{n}^{\circ} 2$ ), le drapé souple et fluide, semblent bien rattacher cette petite Vierge de l'Annonciation au courant stylistique des environs de 1400. 


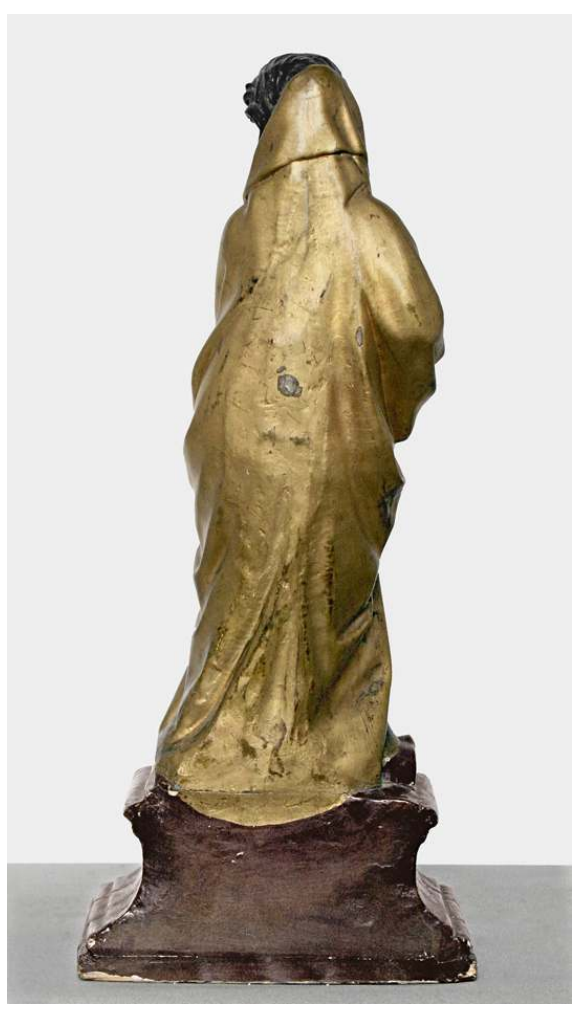

Vierge de l'Annonciation, statuette conservée à l'Hôpital Général de Dijon (Côte-d'Or), revers. JeanPierre Ramot, 2005.

(C) Inventaire général, ADAGP.

Un détail vestimentaire caractéristique vient conforter cette intuition : le voile-manteau replié à l'encolure, remonté haut derrière la nuque comme s'il venait de glisser de la tête. Les miniatures des livres d'heures, aussi bien que la peinture sur panneau de cette époque, en offrent maints exemples. Sur les volets du retable de la Passion peints par Melchior Broederlam pour la chartreuse de Champmol' ${ }^{3}$, la Vierge de l'Annonciation et de la Présentation au Temple présente cette particularité, comme la Vierge à l'Enfant de la collection Frick ${ }^{4}$. La même disposition du voile de la Vierge se retrouve dans les scènes de la Visitation et de la Nativité des Heures du maréchal Boucicaut ${ }^{5}$, l'Annonciation des Très Belles Heures de Notre-Dame ou la Vierge en gloire des Belles Heures de Jean de Berry ${ }^{6}$. Une illustration d'une extrême préciosité en est donnée par la Vierge au croissant de lune d'un livre de prières de Philippe le Hardi dit les Grandes Heures, conservé à la Bibliothèque royale de Bruxelles ${ }^{7}$. Ce schéma a été employé dans d'autres techniques que la peinture, comme l'atteste par exemple la Vierge de l'Annonciation d'un médaillon en ivoire du musée du Louvre ${ }^{8}$.

6 Les pans rapprochés du manteau aux plis moelleux forment des ondulations parallèles quasi géométriques, terminées par un unique enroulement. Ils découvrent le bas de la robe qui s'étale au contact du sol, laissant apparaittre le bout pointu d'un soulier. La retombée assez calme de l'étoffe à l'avant contraste avec les plis superposés en $\mathrm{V}$ plus profondément creusés qui animent les côtés (fig. $\mathbf{n}^{\circ} \mathbf{3}, \mathbf{n}^{\circ} \mathbf{4}$ ). Dans l'agencement du drapé, le motif du manteau retenu sous le bras gauche ne manque pas non plus de références, que ce soit dans la statuaire ou la peinture. Il peut être observé sur le saint Jean du Calvaire au chartreux de Jean de Beaumetz conservé au musée de Cleveland ${ }^{9}$, comme sur l'ange à chape verte du Puits de Moïse à la chartreuse de Champmol ${ }^{10}$. On le remarque encore sur l'ange de l'Annonciation en marbre du Metropolitan Museum ${ }^{11}$, chez la Vierge 
de la Présentation au Temple du musée national du Moyen Âge ${ }^{12}$ et celle du triptyque brodé de Chartres ${ }^{13}$.

Figure 3

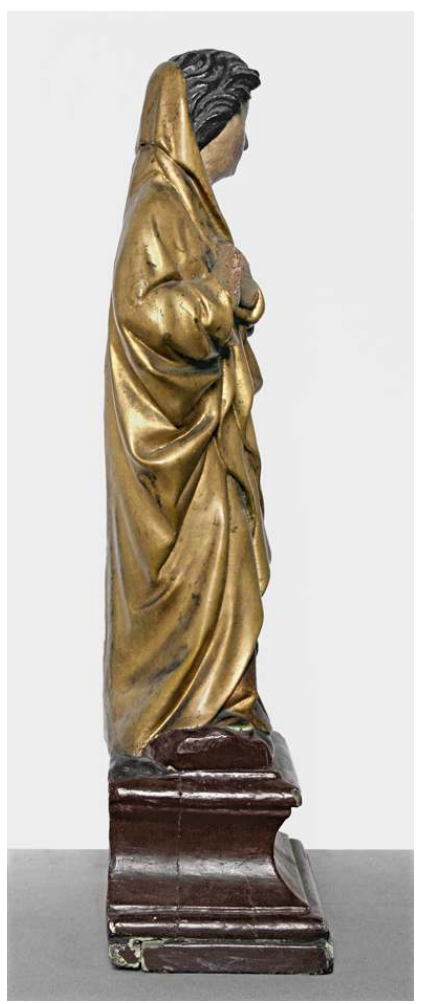

Vierge de l'Annonciation, statuette conservée à l'Hôpital Général de Dijon (Côte-d'Or), profil droit. JeanPierre Ramot, 2005.

(C) Inventaire général, ADAGP. 
Figure 4

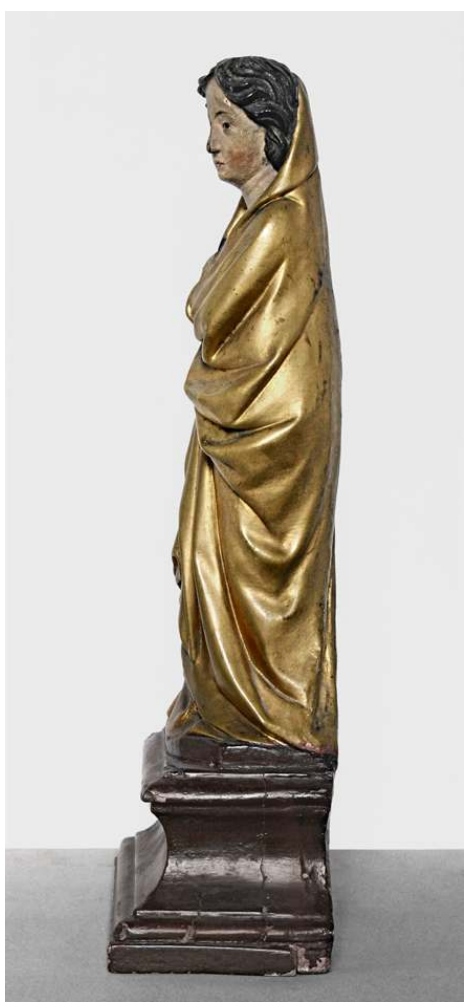

Vierge de l'Annonciation, statuette conservée à l'Hôpital Général de Dijon (Côte-d'Or), profil gauche. Jean-Pierre Ramot, 2005.

(c) Inventaire général, ADAGP.

7 À l'élégance du vêtement répond un visage aux traits délicats: pommettes hautes et menton menu sur un cou un peu enrobé, nez long et droit, petite bouche aux lèvres charnues; le tracé des sourcils et des paupières se distingue plus difficilement sous l'épaisseur de la polychromie. Le front haut est encadré de mèches torsadées, selon une formule usitée pour la coiffure de la Vierge à la charnière des xiv et $\mathrm{xv}^{\mathrm{e}}$ siècles. La mutilation de l'extrémité des doigts de la main droite ne rompt pas le charme de cette image toute empreinte de sérénité et de raffinement. Son matériau, moins pérenne que la pierre ou même que le vélin, ajoute encore à l'intérêt et à la rareté de l'œuvre.

La présence de cette sculpture au sein des collections anciennes de l'Hôpital général peut surprendre si l'on oublie que l'établissement a succédé à une maison fondée en 1204 par le duc de Bourgogne Eudes III et confiée à l'Ordre hospitalier du Saint-Esprit. Cet hôpital a bénéficié ensuite des largesses des ducs Valois, comme en témoigne une miniature de l' Histoire en images de la fondation de l'Hôpital du Saint-Esprit de Dijon: le dernier folio de ce manuscrit enluminé des années 1450-1460 représente Philippe le Bon et Isabelle de Portugal visitant l'hôpital " par grant devocion et illecque firent leurs grandes omosnes » ${ }^{14}$. De l'édifice médiéval subsiste encore la chapelle Sainte-Croix de Jérusalem, fondée en 1459 par le frère Simon Albosset, où sont conservées plusieurs sculptures en pierre du xv ${ }^{\mathrm{e}}$ siècle.

Dans ce contexte, l'existence d'une statuette apparentée au "gothique international » semble moins étrange. La provenance de l'hôpital du Saint-Esprit n'est pas avérée et il serait sans doute téméraire de l'affirmer, tant le patrimoine hospitalier est souvent le 
fruit d'héritages divers, mais l'ancienneté et l'origine ducale de la fondation, comme ses liens privilégiés avec la cour de Bourgogne ne rendent pas cette hypothèse improbable.

\section{NOTES}

1. Voir dans la base Palissy : notice IM21010695 (avec une datation erronée).

2. Dans le cadre de l'enquête thématique sur le patrimoine hospitalier de Bourgogne, 645 notices concernant cet établissement ont été versées en 2006 dans la base Palissy ; 254 objets sont classés Monuments historiques, 88 autres ont été présentés à la Commission départementale des objets mobiliers le 30 mars 2007 et 16, dont cette statuette, ont fait l'objet d'une proposition de classement.

3. Dijon, Musée des Beaux-Arts, inv. CA $1420 \mathrm{~A}$; voir catalogue de l'exposition L'art à la cour de Bourgogne. Le mécénat de Philippe le Hardi et de Jean sans Peur (1364-1415). Dijon : musée des Beaux-Arts, 2004, n 70, p. 196.

4. New York, The Frick Collection, 1927.1.57. Voir VILLELA-PETIT, Inès. Le gothique international. L'art en France au temps de Charles VI. Paris : musée du Louvre et éditions Hazan, 2004, p. 97 et catalogue de l'exposition Paris 1400. Les arts sous Charles VI. Paris : musée du Louvre, 2004, fig. 51, p. 194.

5. Paris, Musée Jacquemart-André, ms. 2. La Visitation (fol. 65 v.) est reproduite dans VILLELAPETIT, Inès. L'art en France au temps de Charles VI. Paris : musée du Louvre et éditions Hazan, 2004, p. 81 ; la Nativité (fol. 73 v.) dans PANOFSKY, Erwin. Les primitifs flamands. Paris : Hazan, 1992, p. 123.

6. Paris 1400. Les arts sous Charles VI. Paris : musée du Louvre, 2004, fig. 9, p. 45 et fig. 96, p. 325.

7. Bruxelles, Bibliothèque royale de Belgique, ms. 11035-37, fol. 6 v.; L'art à la cour de Bourgogne. Le mécénat de Philippe le Hardi et de Jean sans Peur (1364-1415). Dijon : musée des Beaux-Arts, 2004, n 33, p. 107.

8. Paris, musée du Louvre, inv. OA 2770 ; Paris 1400. Les arts sous Charles VI. Paris : musée du Louvre, 2004, n 126, p. 213.

9. Cleveland, The Cleveland Museum of Art, inv. 1964.454 ; L'art à la cour de Bourgogne. Le mécénat de Philippe le Hardi et de Jean sans Peur (1364-1415). Dijon : musée des Beaux-Arts, 2004, p. 200.

10. L'art à la cour de Bourgogne. Le mécénat de Philippe le Hardi et de Jean sans Peur (1364-1415). Dijon : musée des Beaux-Arts, 2004, p. 218, fig. 13 ; voir dans la base Mémoire : notice APMH00020842.

11. New York, The Metropolitan Museum of Art, inv. 17-190-390; L'art à la cour de Bourgogne. Le mécénat de Philippe le Hardi et de Jean sans Peur (1364-1415). Dijon : musée des BeauxArts, 2004, n 120, p. 315.

12. ${ }^{12}$ Paris, musée national du Moyen Âge, inv. Cl. 18849 ; L'art à la cour de Bourgogne. Le mécénat de Philippe le Hardi et de Jean sans Peur (1364-1415). Dijon : musée des Beaux-Arts, $2004, \mathrm{n}^{\circ} 16$, p. 51.

13. Chartres, musée des Beaux-Arts, inv. 2886 ; Paris 1400. Les arts sous Charles VI. Paris : musée du Louvre, 2004, n 148, p. 247. 
14. Dijon, Hôpital général, A H 4, fol. 25. Voir ZALUSKA, Yolanta. « Pierre Crapillet et l'Histoire en images de la fondation de l'Hôpital du Saint-Esprit de Dijon ", in Revue de l'Art, n 84, 1989-2, p. 44-47; voir dans la base Mémoire : notice APMH00019252.

\section{AUTEUR}

\section{ELISABETH RÉVEILLON}

Conservateur du patrimoine. Service Patrimoine et Inventaire, Région Bourgogne. ereveillon@crbourgogne.fr 